\title{
Utilization of retired physicians as nursing faculty
}

\author{
Patricia L. Starck ${ }^{1}$, Shelly Liss ${ }^{2}$, Gerda Gomez ${ }^{1}$, Michael E. Speer ${ }^{3}$ \\ ${ }^{1}$ The University of Texas Health Science Center-Houston School of Nursing, Houston, USA \\ ${ }^{2}$ Department of Physical Medicine \& Rehabilitation, Baylor College of Medicine, Houston, USA \\ ${ }^{3}$ Departments of Pediatrics \& Ethics, Baylor College of Medicine, Houston, USA \\ Email: Patricia.L.Starck@uth.tmc.edu
}

Received 13 September 2013; revised 12 October 2013; accepted 28 October 2013

Copyright (C) 2013 Patricia L. Starck et al. This is an open access article distributed under the Creative Commons Attribution License, which permits unrestricted use, distribution, and reproduction in any medium, provided the original work is properly cited.

\begin{abstract}
The nation's nursing shortage is predicted to worsen, as nurses retire (supply) and more patients have access to care with the full enactment of the Affordable Care Act (demand). Schools of nursing are under continuing pressure to increase enrollment in entry level nursing programs [1-4]. Nurse educators have been engaged in a variety of creative and innovative projects to increase enrollment with some success. A primary reason for the lack of educational capacity is the shortage of nursing faculty [3-7]. The University of Texas Health Science Center-Houston School of Nursing undertook an innovative project to alleviate the nursing faculty shortage at that school. Working with a retired physician group, physician volunteers were solicited to teach in the laboratory portion of an undergraduate health assessment course. Twenty-two physicians volunteered in the first year in a class that involved forty baccalaureate students in their firstsemester. The objectives of the project were twofold: First, to determine the suitability of retired physicians to serve as teachers of baccalaureate nursing students and second, ascertain possible monetary savings by using these physicians. Both of these goals were realized. The students valued the physicians' enthusiasm, wisdom and experience and the cohort of physicians equaled the equivalent of four nursing faculty members. With an average annual faculty salary of $\$ 100,000$, savings were significant.
\end{abstract}

Keywords: Retired Physicians; Supply and Demand; Nursing Faculty Shortage

\section{INTRODUCTION}

There is both an acute and chronic shortage of nurses in the United States [1-4]. Janiszewski determined that the four most important causes for the shortage were the aging workforce (In 1980, 25.1 percent of Registered Nurses were under the age of 30 compared to only 9.1 percent in 2000 [5]), declining enrollment in schools of nursing, the changing work climate, and the poor image of nursing [3]. Indeed, there are many more career opportunities for women in the work force over the last quarter century, particularly within the field of nursing itself [4]. The shortage is particularly troublesome in Texas (Figure 1), and schools of nursing are under considerable pressure to increase enrollment in entry level nursing programs. There are adequate applicants for a field projected to need an increased labor force. The problem is in educational capacity. Specifically, the issue is an inadequate supply of nursing faculty [5-7]. Nurse educators have engaged in various sorts of creative and innovative projects to produce more with less, as well as to invent new models of nursing education [7]. Use of regularly employed nurses as preceptors, use of part-time or contract nursing faculty, use of "loaned faculty" by hospitals, etc. have been tried with varying levels of success and sustainability.

\section{METHODS}

As a result of a casual conversation, the leadership of the University of Texas Health Science Center-Houston School of Nursing evaluated the idea that retired physicians might be able and willing to volunteer their time to teach nursing students. First, enquires were made to the Texas State Board of Nursing to determine whether retired physicians could teach entry level baccalaureate nursing students. The Board determined that they could independently teach non-clinical nursing courses, but not clinical courses unless it was as a co-teacher with a nursing faculty member. Of note, it also was determined that physicians who participate in clinical nursing education are not required to maintain malpractice insurance. The Executive Vice President for Academic Affairs of the University System, a physician, also 


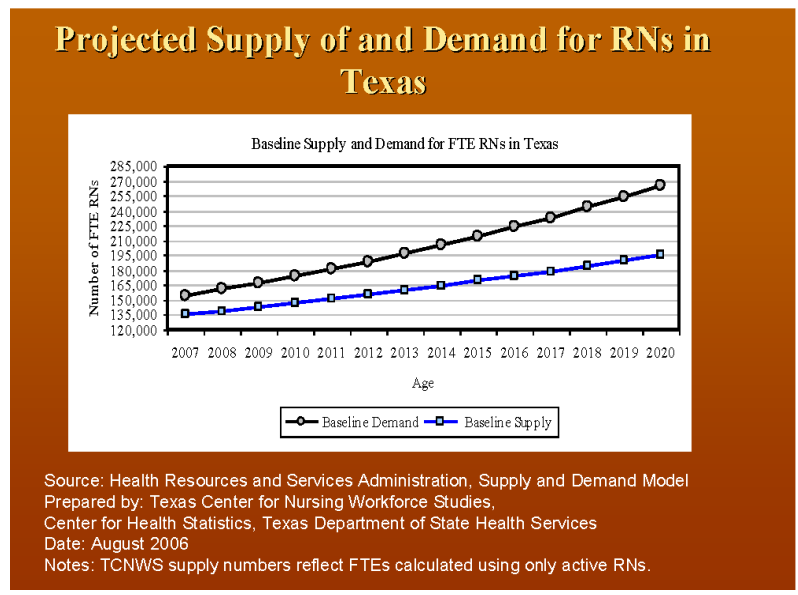

Figure 1. Projected supply and demand for nurses in Texas.

endorsed the concept. After consideration of the options and best fit, it was proposed that retired physicians be invited to teach the laboratory component of the basic undergraduate adult and pediatric health assessment course which is in the first semester of the curriculum. This course consisted of two hours of didactic work per week and three hours in the laboratory conducting a health history and physical exam. Fellow students, programmable manikins, and community citizens served as patients, with creatively arranged symptoms and reactions that generally reflect a combination of pathophysiologic processes.

The Retired Physician Organization (RPO) of Harris County, Texas, a component of the Harris County Medical Society with over 500 active members, was approached for a possible source of volunteer physicians. Utilizing a project management liaison to serve as a bridge between the School of Nursing (SON) administration and faculty and the RPO, volunteer physicians were recruited using the following criteria:

- Retirement within the last five years, or other evidence of staying current with medical practice.

- Teaching experience preferred.

- Computer skills preferred.

In the first semester, there were four lab sections of 10 students each. A course grid was prepared, and the physicians were asked to sign up for one or more individual laboratories.

Before the start of the course, a mandatory 3-hour physician orientation was conducted that focused on understanding current nursing practice, today's student mores', the school's philosophy, and the class curriculum. An optional 2-hour "refresher course" on physical assessment also was offered.

As the physicians needed to know exactly what they were expected to do in the labs and the depth of assessment skills needed to teach beginning nursing students, they were asked to review learning objectives for each laboratory and review the assessment skills demons- tration videos before the laboratories. Weekly reminder emails were sent to the physicians who would be teaching the upcoming week with lab schedules, learning objectives, links to review video, and details of skills covered. The physicians were held accountable for their attendance and for finding replacements when they had a change of plans. To ensure consistency of content taught to the students, each lab began with a demonstration video, followed with a questions-and-answers session. Initially, the students were then divided into pairs to practice physical examination techniques on each other. Later, the students used programmable manikins, and live patients with specific scenarios. The physicians would circulate around the laboratory space to supervise the progress. One nursing faculty floated between four laboratory areas. Following class, students were given one week to finish their assessment write-ups and give them to the faculty that taught that particular laboratory session.

\section{LESSONS LEARNED}

Studies about physician retirement have indicated that physicians desire meaningful work [8,9]. Indeed, physicians expressed their satisfaction in being able to pass along their skills they had honed over decades of practice.

While the RPO's leadership felt that the pilot project was appropriate for their members, the members themselves, due to their many other activities, could not each teach a whole course $[8,9]$. They did agree that a group of physicians could each teach a single laboratory course module, particularly in an area that matched their clinical specialty interest. Initially, 22 physicians volunteered to participate; another 11 joined the program later. Some physicians volunteered for one laboratory session, some for six.

As noted, all volunteer physicians participated in the orientation. Of interest is that all also took part in the optional refresher course on physical assessment. The physicians were observed to be very conscientious in their new role in requesting copies of student assignments, both written materials as well as the online subject matter. They generally arrived early before the lab started. There were no instances where the physicians failed to either appear in person or find an alternative if there was a change in their personal plans.

Student interviews also reflected very positive responses to the change in instruction. Besides developing their clinical skills, they stated that working with the retired physicians offered an invaluable introduction to a mutually respectful physician/nurse interaction and made them very comfortable talking with physicians.

Traditionally, students were given one week to finish their written assessments. However, with a different 
physician teaching in every lab, students did not have the advantage of seeing the same instructors every time they returned to the laboratory. As a consequence, students could not turn in their papers to the instructor who supervised their practice in the content areas they were writing about. It was suggested that the students complete their write-ups within the laboratory session. However, the students had difficulties completing their review of systems and physical examination within the three hours available for the laboratory. While some retired physicians offered their email addresses for students to send their papers after laboratory hours, this was not possible for all. In the latter case, nursing faculty graded the assessments. This problem was solved the next semester when a nursing faculty member was paired with each laboratory section and the students gave their papers to the nursing faculty the next week.

\section{EVALUATION}

In evaluating the experience, the physician questionnaire responses showed that the physicians were very positive in being given the opportunity to share the knowledge and expertise acquired over 40 years with a younger generation and thereby have a positive impact on future patient care. While they admitted to a sense of unease prior to their first teaching experience with nurses, their comfort level immediately improved after seeing the students' obvious pleasure at having experienced, knowledgeable physicians present at their earliest educational experience. The questionnaire also reflected that the physicians were still somewhat uncertain as to exactly what their role should be.

Evaluation focused on the two objectives of effectiveness and cost savings. Evaluations of both the physicians and students were performed. After the end of the course, a questionnaire was mailed to the participating physicians and interviews were conducted with the students. The cost benefit analysis showed a financial benefit to the School by using retired physicians as adjunct faculty. The savings were calculated by determining the number of nursing faculty replaced to conduct the laboratory sessions minus the cost of the pilot program. Expenses included compensated parking, orientation packets, refreshments, a luncheon given at the end of the semester and appreciation gifts (mementos), and a small fee paid to the project liaison for a total of less than $\$ 4000$. Not counted were the costs associated with administrative time spent in recruiting faculty or coordinating schedules.

\section{DISCUSSION}

The number of volunteer physicians (22) initially resulted in an increased time commitment for the Nursing School's faculty to coordinate the different teachers with the different students. This workload was greatly reduced by using the project management liaison who took over this aspect of the course.

In the laboratory component of the basic undergraduate adult and pediatric health assessment course, general health assessment and physical examination techniques are covered. Traditionally, students would have the same instructor throughout the semester for the labs. As most of the physician volunteers were specialists, there was initial concern that the physicians would only sign up for areas involving their specialty. The students related that any disadvantage that this caused was more than compensated by having a specialist for each topic.

The physicians' ability to provide guidance in developing physical exam skills helped the students accomplish the examination with more self confidence and awareness of the "real" world beyond school. Creating a mutually respectful physician/nurse interaction is difficult to replicate in the actual hospital setting due to accessibility and time constraints but is critically important for appropriate team management. This was not difficult in the described environment. Furthermore, the students learned about the diseases and treatments from the medical side as well as from the nursing perspective. This allowed the student to fully integrate the concepts of disease management.

Post pilot project, the specific role of the retired physicians in the educational process was evaluated by the project team. Indicators of the project's success were demonstrated by the feedback from both the students and physicians; 30 physicians volunteered to teach the following semester. The physicians have been integrated into other aspects in the life of the school, including social events. Seminars have been held for physicians, including one as "Understanding generational differences".

Another consideration for the future is to examine the expectations of the nursing school faculty and the volunteer physicians. Considerable time was spent by the project management liaison contacting individual physicians, who had volunteered but were of town or out the country, to determine when they were available for the following semester. Further anticipatory development of course curriculum will permit physicians to plan ahead and facilitate their involvement. It should be noted that once contacted the physicians enthusiastically expressed a desire to continue their participation.

The program began in 2008 and has settled in to a standard part of the BSN degree program. The class size has grown to 120 students. There have been some attrition and change, including two deaths, but new volunteers have also joined.

The inclusion of retired physicians into the teaching environment of the SON has been an extremely enriching experience for our students and faculty and utilizes 
an under realized resource. Although not without its challenges, such programs can serve to alleviate, at least in part, the shortage of nurse faculty in this country.

\section{REFERENCES}

[1] Texas Nursing Education Capacity Team (2012). Texas nursing: Our future depends on it. A strategic plan for the state of Texas to meet nursing workforce needs of 2013. www.dshs.state.tx.us/chs/cnws/TexasTeam/TexasStrateg y.pdf

[2] Texas Nurses Association (2010). RN supply \& demand. http://www.texasnurses.org/displaycommon.cfm?an=1\&s ubarticlenbr $=82$

[3] Janiszewski, G.H. (2003) The nursing shortage in the United States of America: An integrative review of the literature. Journal of Advanced Nursing, 43, 335-343. http://dx.doi.org/10.1046/j.1365-2648.2003.02722_1.x

[4] Fitzpatrick, J. and Emerson, E.E. (2011) 201 careers in nursing. Springer Publishing Company, New York.
[5] United States General Accounting Office (2012) Nursing workforce: Emerging nurse shortages due to multiple factors. United States General Accounting Office Report to the Chairman, Subcommittee on Health, Committee on Ways and Means, House of Representatives. http://www.gao.gov/new.items/d01944.pdf

[6] Reinert, J., Bigelow, A. and Kautz, D.D. (2012) Overcoming nursing faculty shortages and bridging the gap between education and practice. Journal for Nurses in Staff Development, 28, 216-218. http://dx.doi.org/10.1097/NND.0b013e318269fc6c

[7] Tanner, C.A., Gubrud-Howe, P. and Shores, L. (2008) The Oregon Consortium for nursing education: A response to the nursing shortage. Policy Politics Nursing Practice, 9, 203-209. http://dx.doi.org/10.1177/1527154408323043

[8] Virshup, B. and Coombs, R.H. (1993) Physicians' adjustment to retirement. Western Journal of Medicine, 158, 142-144.

[9] Liss, S.E., Cohen, I.M. and Charalampous, K.D. (2001) Insights into physician retirement. Texas Medicine, 97, 72-74. 